\title{
Atribuição de Causalidade ao Sucesso e Fracasso Escolar: Um Estudo Transcultural Brasil-Argentina-México
}

\author{
Maria Cristina Ferreira ${ }^{12}$ \\ EvelineMaria Leal Assmar \\ Universidade Gama Filho, Rio de Janero \\ Alicia Graciela Omar ${ }^{3}$ \\ Consejo Nacional de Investigaciones Cientificas y Técnicas, Argentina \\ Hugo Uribe Delgado \\ Universidad Nacional de Rosario, Argentina \\ Alberto Terrones González \\ Jorge Manue Beltrán Silva \\ Universidad Juárez del Estado de Durango, Méxio \\ Marcos Aguiar deSouza \\ Universidade Federal do Rio deJaneiro \\ Maria do Carmo deFigueiredo Cisne \\ Universidade Estácio de Sá, Rio de Janeiro
}

\begin{abstract}
Resumo
O estudo comparou os mecanismos atribuicionais utilizados por alunos brasileiros, argentinos e mexicanos, ao explicarem o sucesso e fracasso escolar. A amostra compôs-se de 1594 estudantes de bom ou mau rendimento escolar, de ambos os sexos, com idades entre 14 e 20 anos e pertencentes a escolas públicas e particulares de ensino médio, que responderam a um questionário sobre as causas de seu próprio desempenho, do de seus colegas, de alunos de outro tipo de escola e de outras nacionalidades. Os três grupos nacionais adotaram prioritariamente o esforço como causa explicativa do próprio sucesso e fracasso escolar e do de outros alunos, embora tenham ocorrido diferenças entre os padrões atribuicionais, em função da nacionalidade, sexo e tipo de escola. Tais resultados são discutidos com base nos vieses atribuicionais associados à tendência auto-servidora e ao erro fundamental de atribuição e nas peculiaridades culturais que caracterizam os três países.

Palavras-chave: Atribuição de causalidade; desempenho escolar; estudo transcultural.
\end{abstract}

Causal Attribution to Success and Failure in School: A Transcultural Study Brazil-Argentin-Mexico

\begin{abstract}
The attributional mechanisms used by Brazilian, Argentinean and Mexican students to explain the academic success and failure were compared. The sample consisted of 1594 high school students of both sexes separated into either high or low achievement groups, attending either public or private institutions. They were asked to indicate the causes of their own performance, of their classmates, of students from a different kind of school and of students from another country. Effort was chosen by the majority of students from the three national groups as an explanation of either success or failure of their own, of other students from the same country and of students from different countries, albeit observed differences in attributional patterns as a function of nationality, sex and type of school. These results are discussed based both on the self-serving attributional bias and the fundamental attribution error theoretical framework, by taking into account the cultural peculiarities of the three countries which participated in the study.

Keywords: Causal attribution; academic performance; transcultural study.
\end{abstract}

Os graves problemas educacionais, que ainda hoje persistem na América Latina, são comumente apontados como um dos mais sérios entraves ao seu desenvolvimento

\footnotetext{
${ }^{1}$ Endereço para correspondência: Rua Marquês de Valença, 80, 602, 20550030, Tijuca, Rio de Janeiro, RJ. Fone: (21)2569-1176, Fax: (21) 2565-7903. Email: mcris@centroin.com.br

${ }^{2}$ Apoio CNPq.

${ }^{3}$ Apoio ANCyP (Agencia Nacional de Promoción Cientifica y Tecnológica).
}

econômico e social. À falta de políticas públicas que dêem continuidade a projetos de superação gradativa do analfabetismo e promovam a sedimentação de programas de combate aos déficits na formação básica das crianças e adolescentes, mantêm-se bastante elevados os índices de evasão e de repetência escolar.

No Brasil, são tão alarmantes as estatísticas sobre a extensão da crise por que passa a educação nos últimos 50 anos, que melhor seria descrevêla como afetada por um 
estado crônico de insuficiência no cumprimento de suas metas fundamentais, especialmente se o foco de análise se circunscrever aos ensinos fundamental emédio. 0 quadro de fracasso escolar emerge claramente de alguns poucos dados gerais: apenas $43 \%$ das crianças que entram na escola pública concluem o ensino fundamental; menos deum quarto dos alunos concluem as quatro sériesiniciais sem repetência; praticamente dois terços deles estão acima da faixa etária compatível com a sua série (Pilati, 1994).

Talvez por suas condições econômicas e sociais semelhantes, a situação educacional observada nos demais paíseslatino-americanosnão semostra radicalmentediferente da realidade educacional brasileira. Assim éque no México, por exemplo, indicadores recentes sobre educação apontam uma taxa nacional de reprovação de $25 \%$ e uma taxa de evasão em torno de 9\% para o ensino médio regular, enquanto para o ensino médio profissionalizanteessastaxas alcançam 30\% e 31\%, respectivamente (Presidencia de la República, 2000). NaArgentina, o quadro educacional revelase menos alarmante, ainda que não se possa equipará-lo ao padrão dos países do Primeiro Mundo: o índicederepetência nas primeiras séries do ensino médio oscila entre $12 \%$ e $14 \%$, chegando a atingir, em algumas regiões, percentuais superiores e próximos de 20\% (Instituto Nacional de Estadísticas y Censo, 1998).

Talvez mais preocupante que o diagnóstico atual dos sistemas educacionaislatino-americanos seja o prognóstico pouco otimista quanto as suas possibilidades de melhoria a médio prazo. As estimativas de reversão imediata dessas tendências gerais parecem pouco prováveis diante da estabilidade e generalidade com que o fenômeno do fracasso escolar se apresenta na cultura latino-americana, e principalmente dos graves problemas econômicos que enfrentam.

Sob uma visão simplista eapressada, costuma-seafirmar que se 0 aluno não vai bem na escola, isso se deve apenas a suas limitações pessoais - ele não gosta de estudar, ele não consegue aprender, etc. - , atribuindo-selhe a culpa por seu fracasso. Tais explicações tendem, porém, a negligenciar a importância de se incluir os próprios alunos como parte desse processo, isto é, a não considerar o que eles pensam sobre seu próprio desempenho escolar, bem como o de seus colegas.

É nessecontexto queo estudo dosmecanismosutilizados pelaspessoas para explicarem suas próprias condutase ações, e a dos outros, assume particular relevância, pelo grande poder explanatório já demonstrado na análise das situações de realização acadêmica. As atribuições ou explicações causais aos comportamentose/ ou eventostornam-se, assim, ferramentas poderosas para a compreensão das reações frente ao sucesso e fracasso (Heaven, 1989), em função de seu papel mediador entre os estímulos e as respostas individuais.

A abordagem de tal temática tem suas origens no trabalho pioneiro de Heider (1958), segundo o qual as pessoastendem a seutilizar decausasintemas (disposicionais, próprias ao indivíduo) ou externas (situacionais, devidas a circunstâncias físicas ou sociais) para explicar os acontecimentos com os quais se confrontam em seu dia a dia. Tais posições foram posteriormente refinadas e aprofundadas através da teoria das inferências correspondentes de Jones e Davis (1965), que se detiveram no estudo dos mecanismos através dos quais um observador realiza atribuicões internas (disposições pessoais) para as ações de determinados atores, e do modelo de covariação de Kelley (1967), que procurou analisar como os indivíduos processam as informações disponíveis no mundo social e as combinam para chegar às causas dos eventos.

Mais recentemente, Weiner (1986), tendo ainda como referência básica o trabalho de Heider, desenvolveu um modelo de atribuição aplicado a situações de realização, ou seja, à busca de explicações para o sucesso e o fracasso no desempenho de tarefas. Segundo o autor, as explicações causais para situações dessa natureza se enquadram mais freqüentemente em quatro categorias básicas (Habilidade, Esforço, Sorte e Dificuldade da Tarefa), que podem ser classificadas em três dimensões distintas: loaus, que se refere à localização da causa no próprio indivíduo (interna) ou na situação (externa); etabilidade, quediz respeito à natureza temporal da causa, isto é, ao fato de ela perdurar no tempo (estável) ou não (instável) e controlabilidade, queseassocia à influência volitiva que pode (controlável) ou não (incontrolável) ser exercida sobre a causa. Dessa forma, a habilidadeconstitui uma causainterna, estável einoontrolável; o esforço, uma causa intema, instável e controlável; a sorte, uma causa externa, instável e incontrolável e a dificuldade da tarefa, uma causa externa, estável e incontrolável.

Utilizando-se do modelo de atribuição para a formulação de uma teoria de conduta social, Weiner (1995) postula, ainda, que, nos julgamentos de responsabilidade pessoal em situações de realização nas quais os indivíduos obtêm resultados negativos, écomum a atribuição decausas internas e controláveis a estes resultados, especialmente quando não existem circunstâncias atenuantes que possam justificar, em certa medida, a ocorrência de tais eventos.

As formulações de Heider (1958) e dos teóricos que lhe sucederam (Jones \& Davis, 1965; Kelley, 1967; Weiner, 1986) revelaram-se de inestimável valor heurístico, tendo desencadeado um grande número de pesquisas empíricas destinadas a testar uma ampla gama de hipóteses, bem como as possibilidades de aplicação de tais postulados a 
uma variedade de fenômenos e condutas sociais. Essas investigaçõestêm evidenciado queos modelosatribuicionais consistem em esquemas ideais que, em geral, não são adotadosintegralmentepelo percebedor, que, ao contrário, costuma cometer vieses ou distorções ao se engajar em um processo atribuicional.

Entreas distorções cognitivas queinterferem na realização de atribuições causais, o erro fundamental de atribuição (Ross, 1977) se destaca como um dos mais documentados naliteratura. Tal viésatribuicional caracteriza-sepelatendência das pessoas a superestimarem as características disposicionais ea subestimarem ascaracterísticas situacionais, ao explicarem o comportamento do outro.

Contudo, o estudo de Miller (1984), ao comparar as atribuições de crianças e adultos norte-americanos e indianos, verificou, no primeiro grupo, uma referência crescente aos fatores disposicionais e decrescente aos fatores contextuais à medida que aumentava a idade dos sujeitos, enquanto, no segundo grupo, ocorreu o padrão inverso, ou seja, maior número de atribuições externas e menor número de internas, com o aumento da idade. A autora concluiu, assim, que tais diferenças se deviam às diferentes concepções de pessoa compartilhadas pelos dois grupos culturais, isto é, que o erro fundamental de atribuição seria característico das culturas ocidentais, enão de todas as culturas, dada a forte crença que mantêm no valor da responsabilidade pessoal (Jellison \& Green, 1981), do exercício de controle sobre os eventos e os comportamentos (Forgas, Furnham \& Frey, 1990) ou da observância da norma social da internalidade (Beauvois \& Dubois, 1988). A tendência em favor deatribuiçõesinternas estaria, assim, em consonância com o individualismo que predomina nessas culturas.

Em face dessas evidências, que levaram Smith e Bond (1994) a afirmar que o erro fundamental de atribuição não é"fundamental" em culturas coletivistas (Ex.: China, India, Taiwan), outros pesquisadores (Choi \& Nisbett, 1998; Krull \& cols., 1999) defendem a invariância cultural dessefenômeno. Krull ecolaboradores(1999), por exemplo, relatam dois estudos, em que compararam culturas individualistas e coletivistas, com o objetivo de testar a hipótese de que ambas apresentariam 0 viés de correspondência e não difeririam no grau com que manifestariam tal tendência. Comparando asatribuições de estudantes norte-americanos e de Taiwan, por um lado, e de norte-americanos e chineses, por outro, os autores verificaram que ambas as culturas tenderam a inferir, sem diferenças significativas, que a personalidade corresponde ao comportamento, numa demonstração clara dos efeitos do viés de correspondência, concluindo que o erro fundamental de atribuição "merece, de fato, ser chamado de fundamental" (p. 1217).

No que se refere especificamente às auto-atribuições realizadas em situações de realização, um dos vieses mais freqüentemente observados é a tendenciosidade autoservidora (Miller \& Ross, 1975) ou egotismo (Snyder, Stephan \& Rosenfield, 1978), que leva as pessoas a atribuírem, sistematicamente, causas externas ao próprio fracasso e causas internas ao sucesso. Miller e Ross (1975) propõem uma explicação cognitiva para tal viés, enfatizando que as pessoas se responsabilizam pelo próprio sucesso porque ele é percebido como uma decorrência lógica de suas expectativas e de seus esforços para alcançá-lo, o que as leva a superestimar o controle que detêm dessas situações. Já Snyder e colaboradores (1978) associam o egotismo à necessidade de proteção da auto-estima. Marsh, Cairns, Relich, Barnes e Debus (1984), por outro lado, concebem tal fenômeno como uma representação das percepções que os indivíduos têm de suas habilidades, isto é, de seu autoconceito em diferentes áreas, não concordando com a visão de que o mesmo constitui uma distorção generalizada e associada à necessidade de manter uma imagem positiva perante os outros.

A tendência auto-servidora tem sido observada em diversos estudos conduzidos com amostras norteamericanas (Bradley, 1978; Miller \& Ross, 1975; Mullen \& Riordan, 1988; Snyder \& cols., 1978; Whitley \& Frieze, 1985) e asiáticas (Chandler, Shama, Wolf \& Planchard, 1981; Crittenden, 1996; Lee \& Seligman, 1997). Whitley e Frieze (1985), em revisão meta-analítica de 25 estudos conduzidos com crianças norte-americanas de ensino fundamental emédio, também confirmaram a tendência de o sucesso escolar ser atribuído prioritariamente à habilidade eao esforço (causas internas) eo fracasso, à sorte e à dificuldade da tarefa (causas externas). Os autores enfatizam, porém, que tal efeito foi mais pronunciado nos estudos envolvendo auto-atribuições a situações devida real. Estudos posteriores realizados com crianças australianas e norteamericanas deensino fundamental (Bell \& cols., 1994; Marsh \& cols., 1984) constataram, entretanto, que a maior propensão a internalizar a responsabilidade pelo sucesso escolar do que pelo fracasso ocorria principalmente entre os alunos que apresentavam bom rendimento e, conseqüentemente, tinham um melhor auto-conceito.

Fletcher eWard (1988), revendo os estudosatribuicionais realizados em outros contextos culturais, concluíram quea tendenciosidade auto-servidora constituía um fenômeno presente na maioria das culturas, muito embora tenham observado algumas exceções a essa regra. Assim é que, em amostras japonesas (Chandler \& cols., 1981; Kashima \& Triandis, 1986), a tendência predominante tem sido a 
de os indivíduos atribuírem seu sucesso a causas externas e seu fracasso a causas internas.

Em contraste com o quevem sendo sistematicamente documentado na literatura, as pesquisas brasileiras realizadas com estudantes universitários (Dela Coleta \& Godoy, 1986; Maluf \& Marques, 1985) ou com crianças pertencentes às séries iniciais do ensino fundamental de escolas públicas (Boruchovitch \& Martins, 1997; Maluf \& Bardelli, 1991; Neves \& Almeida, 1996) têm sido unânimes em apontar queesses estudantes, independentementedeseu nível de escolaridade, tendem a atribuir seu próprio sucesso nas realizações acadêmicas prioritariamentea causas internas (entre as quais se destaca o esforço). Já o fracasso tende a ser explicado por causas internas (entre as quais se sobressai a falta de esforço) e externas (em especial a dificuldade da tarefa), embora haja uma preferência maior pelas causas internas. Esses resultados indicam, portanto, que os alunos brasileirostendem a seresponsabilizartanto por seus sucessos como por seus fracassos, o que contraria a hipótese da tendenciosidadeauto-servidora quevem sendo comprovada em culturas ocidentais e orientais com alguma regularidade (Whitley \& Frieze, 1985).

Esse panorama geral de resultados permite constatar, então, que não há um padrão muito claro de diferenças culturais nas atribuições realizadas em situações de realização, razão pela qual alguns pesquisadores têm questionado se, nas diferentes culturas, há equivalência de significados das dimensões causais previstas em modelos de atribuição que se originam nas culturas ocidentais (o de Weiner, 1986, principalmente), defendendo a necessidade de identificação de fatores mais específicos de cada cultura (Church \& Lonner, 1998). Ressalte-se, ainda, que, nessa linha de análise, são bastante esparsas as informações sobreas tendências atribuicionais mais típicas de culturas latinas, bem como os estudos transculturais queincluam gruposlatinos. Por outro lado, os resultados destes estudos são também bastanteinconsistentes, como o demonstra a recente revisão realizada por Bempechat, Graham e Jimenez (1999): estudanteslatinos, relativamente a afro-americanos, evidenciam fortes crenças de que 0 fracasso se deve à falta de esforço; crianças latinas tendem mais a atribuir o fracasso à falta de habilidade quando comparadas a crianças anglo-americanas eafro-americanas; imigrantesmexicanoseseusfilhos enfatizam o esforço árduo como um dos aspectos-chave da realização acadêmica.

Em síntese, os estudos sobre atribuição de causalidade realizados em culturas fora do eixo EUA/Europa e Ásia ou em culturas que apresentem desníveis educacionais e socioeconômicos acentuados ainda são praticamente inexistentes, a despeito de esta área caracterizar-se como uma das quevem apresentando maisintensa atividadeteórica e empírica na literatura sociopsicológica, desde a década de 1970. Por outro lado, as investigações conduzidas em contextos de realização têm privilegiado a utilização de situações experimentais, havendo poucas referências na literatura a estudosvoltadosespecificamentepara o contexto escolar, queadotem como alvo o real desempenho do aluno, como forma de se analisar o modo pelo qual os vieses atribuicionais atuam nestas situações. Diante dessa constatação e da discussão quanto à universalidade de certos vieses atribuicionais, o presente trabalho pretendeu identificar e comparar os padrões atribuicionais adotados por alunos brasileiros, argentinos emexicanos, de bom e mau rendimento e pertencentes a escolas privadas e públicas, ao explicarem seu próprio sucesso e fracasso escolar, assim como o de outros alunos pertencentes a sua própria escola, a outro tipo de escola e a outro país.

\section{Método}

\section{Participantes}

A amostra foi composta por 1594 alunos de ambos os sexos, pertencentes a escolas públicas e particulares de ensino médio, com idades variando entre 14 e 20 anos e média de 16,61. Desse total, 541 (234 homens e 307 mulheres) eram argentinos residentesna cidadede Rosário, 492 (244 homens e 236 mulheres) eram brasileiros residentes na cidade do Rio de Janeiro e 561 (207 homens e 354 mulheres) eram mexicanos residentes na cidade de Durango. Em cada classe, dois professores, sendo preferencialmente um deles ligado à área de exatas e 0 outro à área de humanas, designaram cinco alunos de bom rendimento e cinco de mau rendimento, de forma independente um do outro. Nos casos de divergências, eles se reuniram, posteriormente, para chegarem a um consenso a respeito dos alunos a serem efetivamente selecionados para compor a amostra.

\section{Instrumento}

A coleta de dados ocorreu através de um questionário com quatro perguntas, cada uma com cinco alternativas de resposta associadas a causas internas e externas (esforço, inteligência, ajuda da família, dificuldade ou facilidade das provas e ajuda dos colegas). Em cada uma das perguntas, 0 aluno deveria escolher a causa quemelhor explicava seu próprio desempenho (sucesso ou fracasso), assim como o desempenho de um colega (alunos bem sucedidos julgaram alunos mal sucedidos e vice-versa), de um aluno de escola pública ou particular (alunos de bom ou mau desempenho de escolas públicas julgaram, respectivamente, alunos de bom ou mau desempenho de escolas particulares e vice-versa) e de alunos de uma 
outra nacionalidade (brasileiros julgaram argentinos, argentinos julgaram brasileiros e mexicanos julgaram argentinos). $O$ questionário incluiu, ainda, uma pergunta em que o aluno deveria avaliar seu desempenho atual, além de conter perguntas destinadas a recolher informações sociodemográficas. Cumpre registrar que somente aqueles alunos cujas avaliações sobre seu próprio desempenho coincidiram com as avaliações realizadas anteriormentepor seus professores foram incluídos na amostra final.

\section{Procedimento}

A coleta de dados ocorreu nas próprias escolas selecionadas, em horários previamente agendados com a direção e, em geral, após o término do horário regular de aulas. Os participantes foram primeiramente informados dos objetivos do estudo e, em seguida, procederam ao preenchimento dos questionários, em tempo livre.

\section{Resultados}

Inicialmente, foram examinadas as distribuições de freqüências obtidas na amostra total para as respostas a cada uma das quatro perguntas do questionário, ocasião em que se verificou que, em todas elas, as três categorias associadas às causas externas (ajuda em casa, provas fáceis/ difíceis e ajuda dos colegas) apresentaram índices muito baixos de respostas (11 a 23\%), o que levou à decisão de se aglutinarem estas três opções em uma única categoria de respostas rotulada de causas externas. $O$ exame preliminar das distribuições de freqüência daí resultantes revelou que nos diferentes contextos atribuicionais compreendidos pelas quatro perguntas do questionário ocorreu nítida preferência pelo esforço como explicação para o desempenho escolar (64 a 74\% do total de respostas), com a capacidade mantendo-se em posição visivelmente secundária (5\% a 19\% do total de indicações) (Tabela 1).

Em seguida, com o intuito de verificar se os padrões atribuicionais sofriam variações em função das demais variáveis envolvidas no estudo, os dados obtidos foram submetidos a análiseslog-lineares hierárquicas exploratórias. Tal método, de acordo com Iacobucci e McGill (1990), mostra-se particularmente apropriado ao exame das asso ciações existentes em tabelas de contingência multivariadas, nas quais os dados se apresentam em forma de freqüências e os fatores diferenciam-se em categorias. Nesse sentido, as atribuições fornecidas a cada uma das quatro perguntas (variáveis dependentes) foram examinadas separadamente, em suas associações com as variáveis independentes nacionalidade (argentinos, brasileiros e mexicanos), condição do próprio desempenho escolar (bom ou mau desempenho escolar) esexo (masculino efeminino), sendo que na pergunta 3, o tipo de escola (pública ou privada) também entrou na análise.

A análise log-linear com os dados da pergunta que indagava a respeito das causas para o próprio sucesso ou fracasso escolar (pergunta 1) revelou que o modelo mais adequado a sua descrição incluiu o efeito de duas interações de primeira ordem (o que, em um modelo hierárquico, implica que os efeitos principais a elas associados são, também, necessariamente significativos), quais sejam, a condição do próprio desempenho versus nacionalidade e a condição do próprio desempenho versus sexo, conforme indicam os qui-quadrados parciais e os índices de adequação (overall fitting) apresentados na Tabela 2.

Tabela 1

Distribuição deFreqüências Simples ePercentuais das CategoriasC ausais Explicativas dos D iferentes Tipos deD esempenho Escolar Comprendidospelo Estudo

\begin{tabular}{lcccc}
\hline Causas & $\begin{array}{c}\text { Atribuição ao } \\
\text { próprio desempenho }\end{array}$ & $\begin{array}{c}\text { Atribuição ao } \\
\text { desempenho do } \\
\text { colega }\end{array}$ & $\begin{array}{c}\text { Atribuição ao } \\
\text { desempenho de aluno } \\
\text { de outro tipo de escola }\end{array}$ & $\begin{array}{c}\text { Atribuição ao } \\
\text { desempenho de aluno } \\
\text { de outra nacionalidade }\end{array}$ \\
\hline Esforço & $1021(64,5)$ & $1188(74,7)$ & $1127(71,0)$ & $1062(67,1)$ \\
Capacidade & $306(19,3)$ & $225(14,2)$ & $91(5,7)$ & $215(13,6)$ \\
C. externas & $257(16,2)$ & $177(11,1)$ & $369(23,3)$ & $305(19,3)$ \\
Total & $1584(100,0)$ & $1590(100,0)$ & $1587(100,0)$ & $1582(100,0)$
\end{tabular}

Nota. O s diferentes totais devem-se aos erros e omissões (missing values) observados no preenchimento do questionário. 
Tabela 2

$\chi^{2}$ Parciais eÍndices de Adequação dos Modelos Hierárquicos Associados aos DiferentesTipos de A tribuição ao D esempenho Eswlar Comprendidos pelo Estudo

\section{Atribuição ao próprio desempenho (Pergunta 1)}

Índices de adequação: $\chi^{2}(8)=6,04 ; p=0,642 ; G^{2}(8)=5,03 ; p=0,754$

Atribuição X nacionalidade

Efeitos

Atribuição X condição de desempenho

Atribuição X nacionalidade X condição de desempenho

Atribuição X condição de desempenho X sexo

$\begin{array}{rc}\chi^{2} & p \\ 73,88 & \varangle 0,0000 \\ 249,73 & \varangle 0,0000 \\ 37,01 & \varangle 0,0000 \\ 17,53 & \varangle 0,0002\end{array}$

Atribuição ao desempenho do colega (Pergunta 2)

Índices de adequação: $\chi^{2}(16)=18,43 ; p=0,300 ; G^{2}(16)=21,07 ; p=0,176$

\begin{tabular}{lcc}
\hline \multicolumn{1}{c}{ Efeitos } & $\chi^{2}$ & $p$ \\
Atribuição X nacionalidade & 73,88 & $<0,0000$ \\
Atribuição X condição de desempenho & 249,73 & $\varangle 0,0000$
\end{tabular}

Atribuição ao desempenho de aluno de outro tipo de escola (Pergunta 3)

Índices de adequação: $\chi^{2}(29)=30,73 ; p=0,378 ; G^{2}(29)=28,75 ; p=0,478$

\begin{tabular}{|c|c|c|}
\hline $\begin{array}{r}\text { Efeitos } \\
\text { Atribuição X condição de desempenho }\end{array}$ & $\begin{array}{c}\chi^{2} \\
15,46\end{array}$ & $\begin{array}{c}p \\
<0,0004\end{array}$ \\
\hline Atribuição X sexo & 11,94 & $<0,0025$ \\
\hline Atribuição X nacionalidade & 95,99 & $<0,0000$ \\
\hline Atribuição X condição de desempenho X nacionalidade & 15,02 & $<0,0047$ \\
\hline Atribuição X condição de desempenho X sexo & 13,88 & $<0,0010$ \\
\hline Atribuição X nacionalidade X tipo escola & 10,94 & $<0,0272$ \\
\hline
\end{tabular}

Atribuição ao desempenho de alunos de outras nacionalidades (Pergunta 4)

Índices de adequação: $\chi^{2}(10)=14,71 ; p=0,143 ; G^{2}(10)=14,58 ; p=0,148$

\begin{tabular}{lcc}
\hline \multicolumn{1}{c}{ Efeitos } & $\chi^{2}$ & $\mathrm{p}$ \\
Atribuição X condição de desempenho & 43,86 & $<0,0000$ \\
Atribuição X sexo & 27,08 & $\varangle, 0000$ \\
Atribuição X nacionalidade & 36,43 & $<0,0000$ \\
Atrbuição X condição de desempenho X nacionalidade & 65,06 & $\varangle 0,0000$ \\
Atribuição X condição de desempenho X sexo & 8,83 & $<0,0121$ \\
\end{tabular}

Tais resultados, aliados ao exame dos parâmetros estimados para cada célula ${ }^{4}$, evidenciaram que os alunos das três nacionalidades, ao explicarem seu próprio sucesso escolar, utilizaram-secom maior freqüência do esforço, mas também recorreram com relativa freqüência à capacidade,

${ }^{4}$ Os resultados a respeito das estimativas de parâmetros obtidas nas análises log-lineares realizadas nas quatro perguntas do questionário encontram-se à disposição dos interessados, através de contato direto com os autores. como causa explicativa de seu bom desempenho. Contudo, ao explicarem seu próprio fracasso escolar, embora os três grupos tenham se valido prioritariamente do esforço, foi possível verificar queargentinos e mexicanos optaram mais freqüentemente pelo esforço que os brasileiros, os quais, por outro lado, utilizaram-se de causas externas com maior freqüência que os alunos das demais nacionalidades. A registrar, ainda, a quase absoluta inexpressividade da capacidade como razão do próprio fracasso nos três grupos culturais (Tabela3). 
Tabela 3

Distribuição deFrequências SimplesePercentuaisdas CausasAtribuídasao Próprio Deempenho eao Desempenho deAlunos deOutro Tipo deEsolla edeOutras Nacionalidades, em função da Nacionalidadeeda Condição do Próprio D esempenho

Atribuição ao próprio desempenho (Pergunta 1)

\begin{tabular}{|c|c|c|c|c|c|c|}
\hline \multirow[t]{2}{*}{ Causas } & \multicolumn{3}{|c|}{ Bom desempenho escolar } & \multicolumn{3}{|c|}{ Mau desempenho escolar } \\
\hline & Argentinos & Brasileiros & Mexicanos & Argentinos & Brasileiros & Mexicanos \\
\hline Esforço & $145(50,5)$ & $124(47,9)$ & $195(59,3)$ & $223(87,8)$ & $136(61,0)$ & $198(85,3)$ \\
\hline Capacidade & $112(39,0)$ & $84(32,4)$ & $84(25,5)$ & $8(3,1)$ & $3(1,3)$ & $15(6,5)$ \\
\hline C. externas & $30(10,5)$ & $51(19,7)$ & $50(15,2)$ & $23(9,1)$ & $84(37,7)$ & $19(8,2)$ \\
\hline \multicolumn{7}{|c|}{ Atribuição ao desempenho de alunos de outro tipo de escola (Pergunta 3) } \\
\hline \multirow[t]{2}{*}{ Causas } & \multicolumn{3}{|c|}{ Bom desempenho escolar } & \multicolumn{3}{|c|}{ Mau desempenho escolar } \\
\hline & Argentinos & Brasileiros & Mexicanos & Argentinos & Brasileiros & Mexicanos \\
\hline Esforço & $177(61,7)$ & $156(60,5)$ & $265(80,5)$ & $170(66,0)$ & $149(65,6)$ & $210(90,5)$ \\
\hline Capacidade & $20(7,0)$ & $9(3,5)$ & $23(7,0)$ & $26(10,2)$ & $13(5,7)$ & $0(0,0)$ \\
\hline C. externas & $90(31,4)$ & $93(36,0)$ & $41(12,5)$ & $58(22,8)$ & $65(28,6)$ & $22(9,5)$ \\
\hline \multicolumn{7}{|c|}{ Atribuição ao desempenho de alunos de outras nacionalidades (Pergunta 4) } \\
\hline \multirow[t]{2}{*}{ Causas } & \multicolumn{3}{|c|}{ Bom desempenho escolar } & \multicolumn{3}{|c|}{ Mau desempenho escolar } \\
\hline & Argentinos & Brasileiros & Mexicanos & Argentinos & Brasileiros & Mexicanos \\
\hline Esforço & $197(67,2)$ & $187(73,3)$ & $195(59,3)$ & $139(54,7)$ & $138(61,3)$ & $210(90,5)$ \\
\hline Capacidade & $39(13,6)$ & $32(12,5)$ & $83(25,2)$ & $32(12,6)$ & $23(10,2)$ & $6(2,6)$ \\
\hline C. externas & $55(19,2)$ & $36(14,1)$ & $51(15,5)$ & $83(32,7)$ & $64(28,4)$ & $16(6,9)$ \\
\hline
\end{tabular}

Já a interação entre sexo e condição do próprio desempenho indicou que homens e mulheres atribuíram seu sucesso escolar tanto ao esforço quanto à capacidade, porém as mulheres recorreram mais freqüentemente ao esforço que os homens, os quais, por sua vez, valeram-se mais freqüentemente da capacidade que as mulheres, ao explicarem seu bom desempenho escolar. No entanto, os alunos de ambos os sexos usaram nitidamente o esforço como causa prioritária de seu fracasso (Tabela 4).

Os qui-quadrados parciais do modelo mais adequado à explicação dos dados obtidos em resposta à pergunta associada à atribuição do bom ou mau rendimento de um colega de turma (pergunta 2), por alunos mal ou bem sucedidos, respectivamente, bem como seus índices de adequação, encontram-se na Tabela 2. Tal modelo englobou apenas o efeito principal das variáveis nacionalidade e condição do próprio desempenho. Neste sentido, foi demonstrado que os alunos dos três países lançaram mão principalmente do esforço para julgar 0 desempenho de seus colegas, porém os mexicanos utilizaram-no mais freqüentemente que argentinos e brasileiros, os quais, em contrapartida, recorreram mais à capacidade que os mexicanos. Os brasileiros ainda fizeram, também, maior uso de causas externas que os alunos das demais nacionalidades(Tabela 5). Por outro lado, os alunos de bom desempenho escolar, ao julgarem o fracasso de seus colegas, utilizaram basicamente o esforço, porém os alunos de mau desempenho, ao julgarem o sucesso de seus colegas, fizeram uso maisfreqüentedo esforço, mastambém adotaram a capacidade como causa explicativa do êxito acadêmico (Tabela 6).

A análise log-linear da pergunta que solicitava aos alunos de bom ou mau rendimento de escolas públicas que julgassem, respectivamente, as causas do sucesso ou fracasso de alunos de escolas particulares e vice-versa (pergunta 3), revelou que o modelo mais adequado à descrição dos dados compreendia três interações de segunda ordem, quais sejam, a condição do próprio 
Tabela 4

Distribuição de FrequêndasSimplese Percentuais dasCausas A tribuídasao Próprio Dempenho eao Dempenho deAlunos deOutro Tipo deEscola edeOutras Nacionalidades, em função do Sexo eda Condição do Próprio D esempenho

Atribuição ao próprio desempenho (Pergunta 1)

\begin{tabular}{lcccr}
\hline Causas & \multicolumn{2}{c}{ Bom desempenho escolar } & \multicolumn{2}{c}{ Mau desempenho escolar } \\
& Sexo & Sexo & Sexo masculino & Sexo feminino \\
& masculino & feminino & & \\
Esforço & $112(40,6)$ & $352(58,8)$ & $326(80,7)$ & $231(75,7)$ \\
Capacidade & $111(40,2)$ & $169(28,2)$ & $13(3,2)$ & $13(4,3)$ \\
Causas externas & $53(19,2)$ & $78(13,0)$ & $65(16,1)$ & $61(20,0)$ \\
\hline
\end{tabular}

Atribuição ao desempenho de alunos de outro tipo de escola (Pergunta 3)

\begin{tabular}{lccrr}
\hline Causas & \multicolumn{2}{c}{ Bom desempenho escolar } & \multicolumn{2}{c}{ Mau desempenho escolar } \\
& Sexo & Sexo & Sexo masculino & Sexo feminino \\
& masculino & feminino & & \\
Esforço & $184(66,7)$ & $414(69,2)$ & $273(67,2)$ & $256(83,4)$ \\
Capacidade & $14(5,1)$ & $38(6,4)$ & $36(8,9)$ & $3(1,0)$ \\
Causas externas & $78(28,3)$ & $146(24,4)$ & $97(23,9)$ & $48(15,6)$
\end{tabular}

Atribuição ao desempenho de alunos de outras nacionalidades (Pergunta 4)

\begin{tabular}{lcccr}
\hline Causas & \multicolumn{2}{c}{ Bom desempenho escolar } & \multicolumn{2}{c}{ Mau desempenho escolar } \\
& Sexo & Sexo & Sexo masculino & Sexo feminino \\
Esforço & masculino & feminino & & \\
Capacidade & $161(59,4)$ & $414(69,0)$ & $260(64,0)$ & $227(74,4)$ \\
Causas externas & $62(22,9)$ & $92(15,3)$ & $52(12,8)$ & $9(3,0)$ \\
& $48(17,7)$ & $94(15,7)$ & $94(23,2)$ & $69(22,6)$ \\
\hline
\end{tabular}

Tabela 5

Distribuição deFrequêndiasSimplese PercentuaisdasCausas A tribuídas ao Deempenho do Colega em função da Nacionalidade

\begin{tabular}{lrrr}
\hline Causas & Argentinos & Brasileiros & Mexicanos \\
\hline Esforço & $390(72,1)$ & $310(63,5)$ & $488(87,0)$ \\
Capacidade & $107(19,8)$ & $77(15,8)$ & $41(7,3)$ \\
C. externas & $44(8,1)$ & $101(20,7)$ & $32(5,7)$ \\
\hline
\end{tabular}

desempenho com a nacionalidade, a condição do próprio desempenho com o sexo e a nacionalidade com o tipo de escola (Tabela 2). Deste modo, ao explicarem tanto o sucesso quanto o fracasso de alunos de um tipo de escola diferente do seu, os alunos mexicanos bem e mal sucedidos, recorreram com maior freqüência ao esforço que os brasileiros e argentinos, os quais, por sua vez, lançaram mão das causas externas mais freqüentemente que os mexicanos, no julgamento de ambas as situações escolares. Merece destaque o fato de que a capacidade foi pouco cogitada pelos três grupos nacionais como causa explicativa tanto do sucesso quanto do fracasso escolar dos alunos de um outro tipo de escola (Tabela 3).

A interação entre sexo e condição do próprio desempenho revelou que os alunos de bom desempenho de ambos os sexos adotaram o esforço como principal causa explicativa do sucesso de alunos de um outro tipo de escola, recorrendo em segundo lugar a causas externas. No 
Tabela 6

Distribuição deFrequências Simplese Percentuais das CausasA tribuídas ao D empenho do Colega, em função da Condição do Próprio Desempenho

\begin{tabular}{lcc}
\hline & Bom & Mau \\
Causas & desempenho escolar & desempenho escolar \\
\hline Esforço & $756(86,3)$ & $432(60,5)$ \\
Capacidade & $14(1,6)$ & $211(29,6)$ \\
C. externas & $106(12,1)$ & $71(9,9)$ \\
\hline
\end{tabular}

Tabela 7

Distribuição deFrequências Simplese Percentuais das CausasA tribuídasao D esempenho deAlunosdeoutro Tipo deEscola, em função da Nacionalidadeedo Tipo deEscola

\begin{tabular}{lcccccc}
\hline Causas & \multicolumn{3}{c}{ Escolas públicas } & \multicolumn{3}{c}{ Escolas particulares } \\
& Argentinos & Brasileiros & Mexicanos & Argentinos & Brasileiros & Mexicanos \\
\hline Esforço & $228(66,9)$ & $163(69,7)$ & $252(82,4)$ & $119(59,5)$ & $142(56,6)$ & $223(87,5)$ \\
Capacidade & $24(7,0)$ & $9(3,8)$ & $15(4,9)$ & $22(11,0)$ & $13(5,2)$ & $8(3,1)$ \\
C. externas & $89(26,1)$ & $62(26,5)$ & $39(12,7)$ & $59(29,5)$ & $96(38,2)$ & $24(9,4)$
\end{tabular}

entanto, ao serem solicitados a julgar o fracasso escolar de alunos de um outro tipo de escola, os alunos mal sucedidos de sexo feminino atribuíram-no mais freqüentemente ao esforço que os alunos mal sucedidos de sexo masculino (Tabela 4). No que se refere à interação entre tipo de escola e nacionalidade, foi constatado que os alunos das escolas públicas e particulares mexicanas, ao se avaliarem reciprocamente quanto ao bom ou mau desempenho escolar, valeram-se mais freqüentemente do esforço que brasileiros e argentinos que, ao contrário, optaram pela adoção de causas externas como explicação do desempenho mais freqüentemente que os mexicanos (Tabela 7).

O modelo que melhor se adequou às respostas da pergunta relativa à atribuição ao sucesso ou fracasso de alunos de outra nacionalidade (pergunta 4), realizada, respectivamente, por alunos bem e mal sucedidos, compreendeu dois efeitos de interação de primeira ordem, conforme indicado pelos resultados dos qui-quadrados parciais e dos índices de adequação apresentados na Tabela 2. O primeiro efeito associou-se à interação entre condição do próprio desempenho e nacionalidade, numa evidência de que os alunos mexicanos de bom desempenho, ao julgarem o sucesso escolar dos argentinos, adotaram 0 esforço menos freqüentementequeargentinos ebrasileiros, ao se julgarem mutuamente, recorrendo, porém, mais freqüentemente à capacidade que os alunos dos demais grupos. Por outro lado, foram os mexicanos que, ao explicarem o fracasso destes mesmosalunos, fizeram maior uso do esforço, em comparação aos brasileiros eargentinos que, em contraste, fizeram maior uso de causas externas, ao se avaliarem reciprocamente quanto ao mau desempenho escolar(Tabela3). A outra interação significativa relacionouse aos efeitos conjuntos do sexo e da condição do próprio desempenho, demonstrando que os alunos de sexo feminino de bom e mau rendimento realizaram mais atribuições ao esforço que os de sexo masculino, tanto no julgamento do sucesso como no do fracasso dos alunos de outra nacionalidade (Tabela 4).

\section{Discussão}

Fundamentando-se nas proposições de Weiner (1986, 1995) e nos estudos sobre atribuição causal em situações de realização, que têm colocado em evidência o fato de que o componente cultural constitui importantevariável neste processo, o presente estudo pretendeu realizar uma comparação entre os mecanismos atribuicionais mais freqüentementeutilizados por alunos brasileiros, argentinos e mexicanos, de ensino médio, ao explicarem seu próprio sucesso ou fracasso escolar, bem como o de seus colegas, de alunos de outros tipos de escolas e de outras nacionalidades.

Analisando-se de forma global os resultados obtidos, uma evidência que logo se destaca é a predominância do uso decausasinternas em detrimento das externas, em todos os tipos de atribuições e independentemente do alvo e do grupo nacional, o que levou à decisão de se agruparem as diferentescausas externas em umaúnica categoria. Contudo, 
as duas causas internas, quais sejam, esforço e capacidade, foram mantidas como categorias distintas, de modo a que a atividade atributiva dos alunos pudesse ser qualificada não somente sob o prisma da internalidade, mas também sob a ótica das duas outras dimensões conceituais preconizadas por Weiner $(1986,1995)$ estabilidade e controlabilidade - já que o esforço consiste em uma causa interna, porém instável e controlável, enquanto a capacidade define-se como uma causa também interna, mas estável e incontrolável.

Tomar como eixo de discussão tão somente a dicotomia internalidade versus externalidade tenderia, portanto, a simplificar em demasia a análise comparativa, com substancial perda de informação, na medida em queaatribuição interna alcançou percentuais elevadíssimos no conjunto das respostas. Neste sentido, a consideração dos vários significados dimensionais do esforço e da capacidade permitiu a discriminação qualitativa destes padrões atribuicionais.

Atendo-se especificamente aos dados referentes a cada tipo de atribuição, observou-se que, no que diz respeito ao julgamento do próprio desempenho escolar, os alunos das três nacionalidades adotaram prioritariamente 0 efforço ao explicarem seu sucesso, embora tenham recorrido também à capacidade com certa freqüência. A falta de esforço manteve-se também como explicação básica do fracasso nos três grupos, sendo que os brasileiros, adicionalmente, ainda lançaram mão de causas externas. Jáa capacidadefoi imelevantena explicação do mau desempenho escolar.

Tais dados convergem com os resultados de estudos anteriores realizados em amostras latino-americanas, em geral, (Bempechat \& cols., 1999), e em amostras brasileiras, em particular (Boruchovitch \& Martins, 1997; Dela Coleta \& Godoy, 1986; Maluf \& Bardelli, 1991; Maluf \& Marques, 1985; Neves \& Almeida, 1996; Nunes, 1990), mas contrariam resultados obtidos em amostras japonesas (Chandler \& cols., 1981; Kashima \& Triandis, 1986), nas quais se tem verificado a tendência de atribuição do sucesso a causas externas e do fracasso a causas internas. Por outro lado, mostram-se também incongruentes com investigações conduzidas em amostras norte-americanas (Bradley, 1978; Miller \& Ross, 1975; Mullen \& Riordan, 1988; Snyder \& cols., 1976; Whitley \& Frieze, 1985), cujo padrão sistemático tem sido a atribuição do sucesso a causas internas e do fracasso a causas externas, muito embora tal tendência seja mais pronunciada no caso do sucesso do que no do fracasso.

Segundo Snyder e colaboradores (1976), a tendência auto-servidora, observada mais sistematicamente em indivíduos norte-americanos, caracteriza-se pelo fato de as pessoas creditarem a si próprias os sucessos e negarem a responsabilidade por suas falhas. Tal viés sistemático em situações de realização tem como função precípua a auto-promoção (no caso do sucesso) e a proteção da auto-estima (no caso do fracasso), na medida em que a responsabilidade pelo sucesso é motivo de orgulho, porém a responsabilidade pelo fracasso é algo do qual as pessoas se envergonham. Em outras palavras, o viés auto-servidor teria uma função motivacional, isto é, seria uma estratégia que as pessoas adotariam para maximizar o prazer associado ao sucesso e minimizar a insatisfação relacionada ao fracasso.

De acordo com Fiske e Taylor (1991), entretanto, existem mais evidências empíricas a respeito da autopromoção do que da proteção da auto-estima, uma vez que as pessoas, muitas vezes, mostram-se também propensas a assumir a responsabilidade por seu fracasso, sobretudo quando podem atribuí-lo a um fator sobre o qual têm controle. Esta foi justamente a configuração observada nos dados do presente estudo, já que os alunos das três nacionalidades tenderam a atribuir o próprio fracasso principalmente ao esforço, que consiste em uma causa controlável.

Sob a perspectiva do viés auto-servidor, então, isto poderia significar, à primeira vista, que os alunos de mau desempenho acadêmico, ao atribuírem seu fracasso a uma causainterna econtrolável (esforço), estariam provavelmente vivenciando sentimentos de menos valia, e, assim, não estariam lançando mão dos mecanismos de proteção do ego, já quetal recurso implicaria a utilização preferencial de atribuições externas ao próprio fracasso. Considerando-se, entretanto, quea atribuição do fracasso a causasinstáveis faz com que o indivíduo acredite que pode modificar tal resultado no futuro (Weiner, 1986, 1995; Weiner \& cols., 1972), é lícito concluir que estes alunos podem estar atribuindo seu fracasso à falta de esforço (causa interna e instável) como forma desedefenderem defuturosfracassos, na medida em quefazendo este tipo de atribuição estariam se preparando para reverter a situação de desempenho atual, bastando para isso empenharem- se mais em situações análogas no futuro. Levando-se em conta, ainda, o uso da capacidade como segunda causa mais freqüente para explicar o sucesso, mas não o fracasso, pode-se admitir que o viés auto-servidor estaria aí contribuindo, também, de alguma forma, para a regulação da autoimagem dos estudantes.

A utilização prioritária do esforço ocorreu também no julgamento do bom e mau desempenho dos colegas de classe, dos alunos pertencentes a escolas públicas ou particulares e dos alunos de outras nacionalidades. Foi verificado, ainda, que os mexicanos realizaram mais 
atribuições causais ao esforço que argentinos e brasileiros, ao passo que estes dois últimos apontaram com maior freqüência que os mexicanos a capacidade como segunda causa explicativa do desempenho. Prevaleceu, assim, de modo geral, a tendência àutilização de causas disposicionais como determinantes do comportamento, o que se associa ao erro fundamental deatribuição observado primeiramente por Ross (1977) e caracterizado como um viés atribuicional que leva os indivíduos a superestimarem o papel das causas pessoais e a subestimarem o papel das causas situacionais, ao explicarem o comportamento do outro.

De acordo com diversos autores (Forgas \& cols., 1990; Jellison \& Green, 1981; Miller, 1984), esteviés, adquirido gradualmente através de mecanismos de socialização, é típico deculturas individualistas, como a norte-americana, que possuem normas sociais e culturais que valorizam a responsabilidade pessoal na obtenção de metas. Já nas culturas coletivistas, como as asiáticas, por exemplo, este viés não tem sido observado com freqüência (Smith \& Bond, 1994), em virtude de elas se fundamentarem em crenças e normas que assinalam maior ênfase ao grupo e às relações sociais por ele propiciadas.

Em favor dessa posição, Fiske, Kitayama, Markus e Nisbett (1998), analisando dados mais recentes a respeito dos padrões atribuicionais de asiáticos, norte-americanos e europeus, assinalam que os asiáticos, apesar de também fazerem uso de traços disposicionais para explicar 0 comportamento social, preferem as atribuiçõessituacionais, por possuírem uma compreensão mais abrangente do contexto social, definida pela interdependência mútua dos indivíduos que neleseinserem. Conseqüentemente, realizam com maior freqüência atribuições baseadas em fatores situacionais do que atribuições centradas nos fatores disposicionais.

Embora as três culturas latino-americanas aqui contempladas tenham sido enquadradas no pólo coletivista em estudos anteriores (Hofstede, 1997), os dados aqui obtidos revelaram a adoção maciça e sistemática do esforço (causa disposicional, interna e controlável) por parte destes indivíduos, o que permite a conclusão de que estes três grupos nacionais estariam compartilhando de um mesmo traço cultural devalorização da norma de responsabilidade pessoal, que se associa a causas internas e controláveis (Weiner, 1995) e tem se mostrado mais típica de culturas individualistas.

A ênfase na responsabilidade pessoal como norma cultural a ser transmitida e reforçada tem se mostrado instrumento importante para a obtenção do sucesso em diferentes contextos de realização (McClelland, 1961). Daí sedeprendequea priorização desta norma traz implicações

Psiologia: Reflexão e Crítica, 2002, 15(3), pp. 515-527 positivas para o desempenho escolar, foco principal do presentetrabalho.

Dois pontos adicionais merecem, ainda, ser postos em relevo, por fugirem às tendências gerais até aqui discutidas. $\mathrm{O}$ primeiro relaciona-se ao fato de apenas em uma única instância, qual seja, na explicação do sucesso escolar de alunos de outra nacionalidade, os mexicanos terem apresentado menor freqüência de utilização do esforço comparativamente a argentinos e brasileiros. $\mathrm{O}$ segundo ponto diz respeito à consideração decausas externas na explicação do desempenho escolar: enquanto os mexicanostenderam a ignorá-las, os brasileiroseargentinos a elas recorreram com certa freqüência, tanto najustificativa do sucesso quanto na do fracasso, sendo que os brasileiros foram os únicos que também as adotaram ao julgarem 0 próprio fracasso. Investigações posteriores voltadas para estes aspectos específicos e orientadas por uma perspectiva intracultural poderiam contribuir para a identificação dos traços culturais peculiares a cada cultura que estariam subjacentes a tais fenômenos.

No que diz respeito àinfluência do sexo nas atribuições, foi observado queosalunosdesexo feminino, ao explicarem seu próprio sucesso, usaram mais o esforço que os de sexo masculino, que, em contrapartida, fizeram maior uso da capacidadeque as mulheres. Asinvestigações realizadas sobre essa questão nas décadas de setenta e oitenta concluíram que as mulheres, ao fazerem atribuições a seu sucesso acadêmico, eram mais externas que os homens, que, por sua vez, mostravam-se mais internos (Whitley, McHugh \& Frieze, 1986). Mais recentemente, contudo, as diferenças de gênero na atribuição desapareceram ou têm se mostrado muito pouco significativas(Bell \& cols., 1994; Birenbaum \& Kraemer, 1995; Lightbody, Siann, Stocks \& Walsh, 1996; Wigfield, 1988).

Contrariando, assim, as pesquisas mais recentes que apontam para a ausência de diferenças de gênero nas atribuições ao desempenho escolar, os resultados ora obtidos indicam diferenças de gênero na atribuição ao sucesso, com os homens usando mais a capacidade e as mulheres usando mais o esforço. Tais resultados podem ser interpretados à luz dos achados de Hofstede (1997), que, na dimensão feminilidade-masculinidade, situam os três países envolvidos no presente estudo no pólo masculino, o que significa dizer que em todos eles os papéis de gênero são bastante diferenciados socialmente. Nesse sentido, embora as mulheresjá tenham conseguido avanços consideráveis em direção a relações de gênero mais igualitárias, épossível queos adolescentes argentinos, brasileiros e mexicanos ainda estejam sendo submetidos a padrões de socialização de gênero que reforçam a superioridade e a capacidade masculina e a inferioridade 
Maria Cristina Ferreira, Eveline Maria Leal Assmar, Alicia Graciela Omar, Hugo Uribe Delgado, Alberto Terrones González, Jorge Manuel Beltrán Silva, Marcos Aguiar de Souza \& Maria do Carmo de Figueiredo Cisne

feminina, os quais estariam se refletindo em suas autoatribuições ao desempenho acadêmico.

Tomados em conjunto, então, os resultados da presente investigação evidenciaram quea causa básica aque os alunos mexicanos, argentinos e brasileiros se referenciam, ao explicarem seu próprio desempenho acadêmico e o de outros alunos, sejam eles bem ou mal sucedidos, estudem em escolas públicas ou particulares e pertençam a seu próprio país ou a outro país é o esforço, seguido, a certa distância, da capacidade, especialmente quando se trata de explicar o sucesso escolar. Em síntese, em que pesem as diferenças culturais existentes entre os três países que participaram do estudo, foi possível constatar queseusalunos possuem padrões atribuicionais similares e caracterizados pela internalidade, apesar de apresentarem, também, certas idiossincrasias que os diferenciam em alguns aspectos.

Seria interessante, portanto, que futuras investigações procurassem aprofundar a compreensão dos mecanismos cognitivos e motivacionais que atuam como mediadores das atribuições causais ao desempenho escolar, através de estudos qualitativos que, ao invés de apresentarem aos participantes uma série de causas previamente selecionadas pelos pesquisador, utilizem perguntas abertas que permitam não só a indicacão de outros tipos de causas, como também o significado dimensional que elas têm para os alunos. $\mathrm{O}$ estudo dos fatores psicológicos, sociais e econômicos responsáveis pelo fracasso escolar é tarefa prioritária a qualquer país que valoriza e investe no bem-estar de seus cidadãos. Alinhado com esta perspectiva, o presentetrabalho representa uma iniciativa nesta direção, disponibilizando resultados que poderão ser úteis à formulação e planejamento de políticas públicas destinadas a melhorar 0 panorama geral da educação nos três países latinoamericanos aqui representados, com a conseqüenteredução dos índices de evasão e repetência escolar.

\section{Referências}

Beauvois, J. L. \& Dubois, N. (1988). The norm of internality in the explanation of psychological events. European Journal of Social Psychology, 18, 299-316.

Bell, S. M., McCallum, R. S., Bryles, J., Driesler, K., McDonald, J., Park, S. H. \& Williams, A. (1994). Attributions for academic success and failure: An individual difference investigation of academic achievement. Journal of Psychoeducational Assesment, 12, 4-13.

Bempechat, J., Graham, S. E. \& Gimenez, N. V. (1999). The socialization of achievement in poor and minority students. Journal of Cross-Cultural Psychology, 30, 139-158.

Birenbaum, M. \& Kraemer, R. (1995). Gender and ethnic-group differences in causal attributions for success and failure in mathematics and language examinations. Journal of CrossCutural Psychology, 26, 342-359.

Boruchovitch, E. \& Martins, M. L. (1997). As atribuições de causalidade para o sucesso e fracasso escolar e a motivação para a aprendizagem de crianças brasileiras. Arquivos Brasileiros de Psiologia, 49, 59-70.
Bradley, G. W. (1978). Self-serving biases in the attribution process: A reexamination of the fact or fiction question. Journal of Personality and Social Psychology, 36, 56-71.

Chandler, T. A., Shama, D. D., Wolf, F. M. \& Planchard, S. K. (1981). Multiattributional causality: A five cross-national samples study. Journal of Cross-Cultural Psychology, 12, 207-221.

Choi, I. \& Nisbett. R. E. (1998). Situational salience and cultural differences in the correspondence bias and in the actor-observer bias. Personality and Social Psychology Bulletin, 24, 949-960.

Church. A. T. \& Lonner, W. J. (1998). The cross-cultural perspective in the study of personality: Rationale and current research. Journal of CrossCultural Psychology, 29, 32-62.

Crittenden, K. S. (1996). Causal attribution processes among the Chinese. Em M. H. Bond (Org.), The handbook of Chinese psychology (pp. 263-279). Hong Kong: Oxford University Press.

Dela Coleta, J. A. \& Godoy, S. A. (1986). Atribuição de causalidade ao sucesso e fracasso e reações emocionais: Pesquisas brasileiras com os modelos de Bernard Weiner. Psiologia: Teoria e Pesquisa, 2, 145-156.

Fiske, A. P., Kitayama, S., Markus, H. R. \& Nisbett, R. E. (1998). The cultural matrix of social psychology. Em D. Gilbert, S. Fiske \& G. Lindzey (Orgs.), The handbook of Social Psychology (Vol. 2, pp. 915-98) (14를. ed.). New York: McGraw-Hill.

Fiske, S. T. \& Taylor, S. E. (1991). Social ognition. New York: McGraw-Hill.

Fletcher, G. J. O. \& Ward, C. (1988). Attribution theory and processes: A cross-cultural perspective. Em M. H. Bond (Org,), The cross-cultural challenge to Social Psychology (pp. 230-244). Newbury Park, CA: Sage.

Forgas, J. P., Furnham, A. \& Frey, D. (1990). Cross-national differences in attributions of wealth and economic success. Journal of Personality and Social Psychology, 129, 643-657.

Heaven, P. C. L. (1989). Economic locus of control beliefs and lay attribution of poverty. Australian Journal of Psychology, 41, 315-325.

Heider, F. (1958). The psychology of interpersonal relations. New York: Wiley.

Hofstede, G. (1997). Cultures and organizations: Software of the mind. New York: McGraw-Hill.

Iacobucci, D. \& McGill, A. L. (1990). Analysis of attibution data: Theory testing and effects estimation. Journal of Personality and Social Psychology, $59,426-441$.

Instituto Nacional de Estadísticas y Censo (1998). La esolaridad argentina en números: Informe anual. Buenos Aires: Autor.

Jellison, J. M. \& Green, J. (1981). A self-presentation approach to the fundamental attribution error: The norm of internality. Journal of Personality and Social Psychology, 40, 643-649.

Jones, E. E. \& Davis, K. E. (1965). From acts to dispostitons: The attribution process in person perception. Em L. Berkowitz (Org.), Advanoes in experimental social psychology (Vol. 2, pp. 220-226). New York: Academic Press.

Kashima, Y. \& Triandis, H.C. (1986). The self-serving bias in attributions as a coping strategy: A cross-cultural study. Journal of Cross-Cultural Psychology, 17, 83-97.

Kelley. H. H. (1967). Attribution theory in social psychology. Em D. Levine (Org.), Nebraska Symposium on Motivation,15 (pp. 192-238). Lincoln: University of Nebraska Press.

Krull, D. S., Loy, M. H. M., Lin, J., Wang, C. F., Chen, S. \& Zhao, X. (1999). The fundamental fundamental attribution error: Correspondence bias in individualist and collectivist cultures. Personality and Social Psychology Bulletin, 25, 1208-1219.

Lee, Y. T. \& Seligman, M. E. P. (1997). Are the Americans more optimistic than the Chinese? Personality and Social Psychology Bulletin, 23, 32-40.

Lightbody, P., Siann, G., Stocks, R. \& Walsh, D. (1996). Motivation and attribution at secondary school: The role of gender. Educational Studies, 22, 13-25.

Maluf, M. R. \& Bardelli, C. (1991). As causas do fracasso escolar na perspectiva de professoras e alunos de uma escola de primeiro grau. Psicologia: Teoria e Pesquisa, 7, 263-271. 
Maluf, M. R. \& Marques, D. C. (1985). Experiências de sucesso e fracasso escolar e atribuição causal em estudantes universitários. Fórum Educadional, 9, 74-87.

Marsh, H., Cairns, L., Relich, J. Barnes, J. \& Debus, R. L. (1984). The relationship between dimensions of self-attribution and dimensions of self-concept. Journal of Educational Psychology, 76, 3-32.

McClelland, D. C. (1961). The achieving society. Princeton, NJ: Van Nostrand Reinhold.

Miller, J. G. (1984). Culture and the development of everyday social explanantion. Journal of Personality and Social Psychology, 46, 961-978.

Miller, D. T. \& Ross, M. (1975). Self-serving biases in the attribution of causality: Fact ot fiction? Psychological Bulletin, 82, 213-225.

Mullen, B. \& Riordan, C. A. (1988). Self-serving attributions for performance in naturalistic settings: A meta-analytic review. Journal of Applied Social Psychology, 18, 3-22.

Neves, M. M. B. J. \& Almeida, S. F. C. (1996). O fracasso escolar na 5a série na perspectiva de alunos repetentes, seus pais e professores. Psiologia: Teoria e Pesquisa, 12, 147-156.

Nunes, A. N. A. (1990). Fracasso escolar e desamparo adquirido. Psioologia: Teoria e Pesquisa, 6, 139-154.

Pilati, O. (1994). Sistema nacional de avaliação da educação básica (SAEB): Ensaio. Avaliação das Políticas Públicas Educadionais, 2, 11-30.

Presidencia de la Republica (2000). Sexto informe de gobierno: Anexo Estadístio. México: Autor.

Ross, L. (1977). The intuitive psychologist and his shortcomings: Distorions in the attribution process. Em L. Berkowitz (Org.), Advanoes in experimental Social Psychology (Vol. 10, pp.174-221). New York: Academic Press.
Smith, P. B. \& Bond, M. H. (1994). Social psychology across altures Analysis and perspectives. Boston: Allyn and Bacon.

Snyder, M. L., Stephan, W. G. \& Rosenfield, D. (1976). Egotism and attribution. Journal of Personality and Social Psychology, 33, 435-441.

Weiner, B. (1986). An attributional theory of motivation and emotion. New York: Springer-Verlag.

Weiner, B. (1995). Judgements of responsability: A foundation for a theory of social conduct. New York: The Guilford Press.

Weiner, B., Frieze, I., Kukla, A., Reed, S., Rest, S. \& Rosenbaum, R. M. (1972). Perceiving the causes of success and failure. Em J. J. Jones, D. E. Kanouse, H. H. Kelley, R. E. Nisbett, S. Valins \& B. Weiner (Orgs.), Attribution: Peroiving the causes of behavior (pp. 95-120). Morristown, NJ: General Learning Press.

Wigfield, A. (1988). Children's attributions for success and failure: Effects of age and attentional focus. Journal of Educational Psychology, 80, 76-81.

Whitley. B. E. \& Frieze, I. H. (1985). Children's causal attibutions for success and failure in achievement settings: A meta-analysis. Journal of Educational Psychology, 5, 608-616.

Whitley, B. E., McHugh, M. C. \& Frieze, I. H. (1986). Assessing the theoretical models for sex differences in causal attributions of success and failure. Em J. S. Hyde \& M. C. Linn (Orgs.), The psychology of gender: Advanœs through meta-analysis (pp. 102-135). Baltimore: John Hopkins University Press.
Recebido: 18/09/2001

1. Revisão: $16 / 11 / 2001$

2a Revisão: 19/04/2002

Acite Final: 14/05/2002

Sobre os autores

Maria Cristina Ferreira éD outora em Psicologia, Professora do Prgrama dePós-Graduação em Educação da Universidade Gama Filho.

Eveline Maria Leal Assmar éD outora em Psicologia, Professora do Programa dePós-Graduação em Psicologia da Universidade Gama Filho.

Alicia Graciela Omar é Doutora em Psicologia, Pesquisadora do Consejo Nacional de InvestigacionesCientíficas y Tecnicas e Professora da Universidad Nacional de Rosario.

Hugo Uribe Delgado é Mestre em Sociologia, Professor Adjunto da Universidad Abierta Interamericana.

Alberto Terrones González éPsicólogo, Professor do Instituto de Investigación Científica dela Universidad Juaréz del Estado de Durango.

Jorge Manuel Beltrán Silva émédico-cirurgião, professorda Facultad deMedicina delaUniversidad Juárez del Estado de Durango.

Marcos Aguiar de Souza éMestree Doutorando em Psicologia, Professor do Instituto deEducação da Universidade Federal Rural do Rio deJaneiro.

Maria do Carmo de Figueiredo Cisne éMestreem Psicologia, Professora da UniversidadeEstácio de Sá. 